\title{
Exploring the Visitors' Perceptions and Experiences of Museums
}

\author{
Eda Gurel and Axel Nielsen
}

\begin{abstract}
In order to increase visitor numbers and survive in the long run, today's museums need to understand their visiting publics including cultural tourists. Therefore, this chapter aims to understand various publics, their perceptions and experiences of museums by conducting a qualitative research. The study sample was selected from among the visitors of two main museums in Genoa, Italy. Face-to face interviews were conducted to gather data on the definition of a museum by the visitors. The analyses of 372 usable responses revealed seven core elements of museum visitor experiences which included experiences that provide historical and/ or cultural reminisce and awareness, learning and self-development, exposure to tangible evidences, sensory stimulation, wonder and discovery, entertainment and socializing. Implications are discussed relative to marketing strategies.
\end{abstract}

\section{Introduction}

Following budget cuts and increasing competition, museums' need to engage with the tourism market is stronger than at any time in the past. Today, museums with their famous brands and iconic buildings are trying to attract cultural tourists. However, such assets would quickly turn to cliché by treating the cultural tourism market as undifferentiated. Nevertheless, recent research findings (e.g. Pulido-Fernandez and Sanchez-Rivero 2010) suggest that today's cultural tourists are individuals from a variety of backgrounds, with a variety of interests looking for different experiences. Museums of all types are in need to satisfy these tourists. More than just brands and buildings, as great storytellers, museums offer inspiration and information through their collections, exhibitions and events. Today, there is an

E. Gurel $(\square)$

Bilkent University, Ankara, Turkey

e-mail: eda@tourism.bilkent.edu.tr

A. Nielsen

Nielsen Restauri, Genoa, Italy

(C) Springer International Publishing AG, part of Springer Nature 2018

M. Kozak and N. Kozak (eds.), Tourist Behavior, Tourism, Hospitality \& Event

Management, https://doi.org/10.1007/978-3-319-78553-0_10 
opportunity for all museums to engage cultural tourists by understanding and connecting with them (Malde 2013).

There is no consensus on the definition of cultural tourism (Günlü et al. 2009). In a report compiled for International Centre for the Study of the Preservation and the Restoration of Cultural Property (ICCROM) - created by UNESCO as an intergovernmental organization dedicated to the conservation of cultural heritage, cultural tourism is defined as "that form of tourism whose object is, among other aims, the discovery of monuments and sites. It exerts on these last a very positive effect insofar as it contributes - to satisfy its own ends - to their maintenance and protection. This form of tourism justifies in fact the efforts which said maintenance and protection demand of the human community because of the socio-cultural and economic benefits which they bestow on all the population concerned" (ICCROM 2005: 25). According to Richards (1994), "cultural tourism includes visits to historic buildings and sites, museums, art galleries and also to view contemporary paintings or sculpture or to attend the performing arts" (Richards 1994 quoted in Hughes 1996: 707).

Highlighting the important role of museums as places for education, study and enjoyment, International Council of Museums (ICOM) adopted the following definition during the 21st General Conference in Vienna, Austria in 2007; "A museum is a non-profit, permanent institution in the service of society and its development, open to the public, which acquires, conserves, researches, communicates and exhibits the tangible and intangible heritage of humanity and its environment for the purposes of education, study and enjoyment" (ICOM 2014: para 1).

Therefore, framed within the field of cultural tourism, the current research is focused on the case of museums. Kotler and Kotler (1998: 105) also pointed out that museum visitors have a strong link to tourism, since tourists are a part of the audiences and for some museums even a large part of the total number of visitors. Therefore, it is important for museums to understand what kind of visitors tourists are and their relationship with the museum.

In this regard, the aim of this research is to explore visitors' perceptions of the meaning, value and benefits of museum experiences. In the area of marketing, since Schmitt (1999) proposed the term "experience marketing", scholars discuss the content of experience and agree on the fact that experience usually includes various elements (Sheng and Chen 2012). However, as pointed out by Sheng and Chen (2012), studies specific to museums have not clearly defined visitor experience in museums yet. Therefore, addressing this gap in literature, by examining visitors' definition of a museum, this research aims to understand what museums mean, what meanings visitors take away from their museum experiences and how they derive value and benefits from museum-going, in the hope that the content of experience in museums can be defined.

This research is important in the sense that its findings can help in the development and marketing of museums and other cultural heritage-based tourism products and as a result can contribute to the conservation of the tangible and intangible heritage. Through the enjoyment of cultural heritage, museums can help 
develop a climate of public awareness of the value of cultural heritage, conservation and protection in people of all ages and socio-economic groups with different life-styles.

\section{Museum Attendance and Experience}

Yau (2001), a curator of the Hong Kong Museum of History, points out that in the past, museums were collection-oriented, that is, responsible for collecting and preserving artifacts of human experience and relevance and using them in creating and disseminating knowledge through research, educational activities and permanent and temporary exhibitions. However, today, museums are becoming more people-oriented. With the help of the museology concept introduced as early as the 1980s, as stated by Hooper-Greenhill (1994), "museums are changing from being static storehouses for artifacts into active learning environments for people" (Yau 2001: para 1).

With this radical shift in museum function, purpose and priorities, museums have assumed a new role of defining themselves as places for learning and enjoyment, where visitors do not merely view the collections but learn about them with excitement and enhanced interest. It appears that today, the public is looking for a kind of "infotainment/edutainment" from museums; a combination of information/education and entertainment (Yau 2001: para 2). John Lewis, chairman of the Wallace Collection in London, states that museums are now driven to become a branch of the entertainment and education industries rather than the academic institutions they used to be (Newsweek 2004). As a result, today's museums are combining their traditional, functional role with their new, purposive role. The functional role is object-based and relates to activities involving collecting, preserving and displaying these objects. The purposive role, however, requires museums to focus on visitor services to aid society and its development by means of study, education and enjoyment. Therefore, today museums are for people to enjoy and learn from collections held in trust for society (Rentschler 2007).

As a result of this new understanding in museology, museums are increasingly using marketing tools and techniques to achieve greater visibility, to enlarge their offerings, to develop a broader audience and to raise income (Gilmore and Rentschler 2002; Kotler and Kotler 2000). In the area of museum marketing, a substantial amount of effort focuses on audience research to help managers profile their visiting publics (Harrison and Shaw 2004). Nevertheless, as Kotler et al. (2008: 117) point out, "the first thing a museum should do is to understand the characteristics of its current consumers and the segments they represent". By understanding the demographic profiles of their audiences, museums can distinguish their existing audiences in relation to potential audiences (Kotler et al. 2008) and differentiate their marketing mix for the different segments to meet the needs of their various visitors (Morris Hargreaves McIntyre 2007). 
A large number of citizens are uninterested in museums (McLean 1995). It was found that one-third of museum goers never enter a gallery; they spend all their time in the museum shop or the café (Thyne 2001). According to a December 2004 European Group on Museum Statistics (EGMUS) report, within the aggregate population (380.4 million) of the original $15 \mathrm{EU}$ countries, $29.9 \%$ had visited a museum in the previous 12 months (EGMUS 2004). Based on EGMUS' (2007) most recent survey on European cultural values, conducted by interviewing 26,755 citizens in $27 \mathrm{EU}$ member states, $41 \%$ of participants had visited a museum or a gallery at least once in the previous 12 months whereas only $7 \%$ had visited a museum or a gallery more than five times in the previous 12 months (EGMUS 2007).

Museums are mostly visited by women (56\%) and people between 35 and 44 years old (26\%) (Museums, Libraries, and Archives Council [MLA] 2005). Young adults aged 15-24 years old with no children have the lowest average-visit frequency; this age group is also the most under-represented in museum and gallery visitors (Market Opinion and Research International [MORI] 2004). The main reason for visiting a specific museum is interest in the collection (40\%). Good communication and advertising seem to positively affect museum attendance (MORI 2004).

Social scientists at Cambridge University find that education and social status are the two most important factors influencing arts participation (Heritage Lottery Fund [HLF] 2012). The UK's Department for Culture, Media and Sport (DCMS) launched in 2005 and reaches an annual sample size of 29,000 adults finds that visiting museums and galleries, heritage sites and archives is influenced by gender, educational attainment, socio-economic group and economic status. The probability of visiting a museum increases with age and the extent that people visited museums when they were young. In other words, those who visited museums as children are more likely to visit museums as adults. In fact, this effect is maintained one's entire life (DCMS 2010). Accordingly, Yen and Lin (2005) claim that, the growth and future of museums rests in better understanding the behavior of repeat visitors. As MORI (2005) suggested, 59\% of visitors are repeat visitors of a particular museum or a gallery. Of these repeat visitors, almost three quarters (73\%) had already visited in the previous 12 months.

Regarding perceptions of publics, Arts Council of England (ACE) (2013) investigated both visiting and non-visiting public perceptions of and attitudes to the roles and purposes of museums in society. By interviewing 90 participants, it was found that there is strong positive emotional attachment to museums by both visitors and non-visitors. It was also found that participants had a relatively sophisticated understanding of museums as shaping our future as well as past. However, Lin (2006) says, the general public perceives museums as places for education and learning thus they are boring and dull places; not suitable for leisure purposes. Such perceptions prevent non-visitors from visiting museums.

Today, consumers look for unique, memorable and extraordinary experiences (Hosany and Witham 2009). According to Pine and Gilmore (1999), the history of economy advanced in four stages; agrarian economy, industrial economy, service 
economy and emerging experience economy (Dirsehan and Çelik 2011). In the economic value progression today, in order to be successful, marketing managers should understand the consumption experiences of their consumers so that they can provide unforgettable and satisfactory experiences to them (Pine and Gilmore 1999). While, from a business perspective, "experiences are events that engage individuals in a personal way" (Pine and Gilmore 1999: 12), from a consumer perspective, "experiences are enjoyable, engaging, memorable encounters for those consuming these events" (Oh et al. 2007).

In an experiential perspective, consumption provokes sensations and emotions, even more they touch upon the consumer's search for an identity (Caru and Cova 2008). As Caru and Cova (2006) state, a consumer is interested in producing his/her own identity with the help of the consumption experiences and quotes from Firat et al. (1995: 5) that he/she therefore "seeks to experience immersion into thematic settings rather than merely encounter finished products".

Accordingly, Pine and Gilmore (1999) identify four realms of consumer experiences differentiated based on two levels; degree of consumer involvement (passive vs. active participation) and the desire with which the consumer connects or engages with the event/performance (absorption vs. immersion). Accordingly, the four dimensions of experiences include entertainment (passive/absorption), educational (active/absorption), escapist (active/immersion) and aesthetic (passive/ immersion). While the entertainment and aesthetic dimensions involve passive participation in which consumers do not affect or influence the experiential outcome, the educational and escapist dimensions involve active participation whereby consumers play a key role in their experiences. Accordingly, in the framework of Pine and Gilmore (1999), companies aim to delight and entertain their patrons with entertaining experiences. On the contrary, by offering educational experiences they stimulate consumers' mind and appeal to their desire to learn something new. Providing highly immersive experiences, escapist experiences completely absorb individuals in the activity. Finally, aesthetic dimension is related to consumers' interpretation of the physical environment around them. Eventually, these four dimensions combine to form the optimal consumer experience (Hosany and Witham 2009) where an individual is transported emotionally through the experience (Roberson 2011).

Studies specific to museums have identified the reasons for visiting and not visiting a museum to better understand the museum visitor experience (Prentice et al. 1997). Indeed, visitors come to museums for various different reasons. MORI findings (2004) show that, people mainly visit museums because of general interest, willingness to visit the same museum again and interest in a specific temporary exhibition. The group's 2005 findings suggest that although people may have a lack of awareness about museums and their events and exhibitions, there is a strong tradition of taking children to museums (MORI 2005). Fitchett (1997) also finds that there are many reasons for visiting museums, however learning is rarely one of them. Conversely, Falk and Dierking (1992), Jansen-Verbeke and van Rekom (1996) and McLean (1994) identify "learning" as the principal motive for visiting a museum. Defining the museum experience as engaging people "in educationally 
enjoyable experiences from which they take their own personal meaning" (Falk and Dierking 2000: 76), Falk and Dierking (1992) suggest that visitor experience is a dynamic process including experiences before, during and after the visit. In order to explore visitor experiences, first, it is necessary to understand visitor expectations before the visit (Sheng and Chen 2012).

Accordingly, Falk (2009) proposes an interactive experience model with three elements; the personal, socio-cultural and physical contexts to understand visitor experiences in museums. As he argues that each museum visit experience is strongly shaped by the identity-related needs of the visitors, he identifies five main motivations: "(1) explorers: motivated by a need to satisfy personal curiosity or a general interest in discovering more about the topic or subject matter of the institution, (2) facilitators: motivated by the wish to spend quality time in a convenient, attractive and educationally supportive space with someone whom they care about; (3) experience seekers: as mostly made up of tourists, typically motivated to visit primarily to "collect" an experience to feel like that they "have been there and done that"; (4) professional/hobbyists: as the most critical visitors with content expertise, they desire to further specific intellectual needs in an innovative, engaging and educational setting with a specific subject-matter focus; (5) rechargers: desire to reflect, rejuvenate or relax in a beautiful and refreshing environment.

In a similar vein, research consultants Morris Hargreaves McIntyre (2007) identified and quantified the range of motivations that people have for visiting museums and galleries in the UK. Their classification identified four key drivers: social, intellectual, emotional and spiritual. Individuals with social drivers see museums as an enjoyable place to spend time with friends and family and they look for ease of access and orientation, good facilities and services and welcoming staff. Individuals with intellectual drivers are keen to foster their children's or their own interest and knowledge, may have professional interest in the subject, look for a journey of discovery and to find out new things. Individuals with emotional drivers may have a personal connection to the subject matter, desire to see fascinating objects in an inspiring setting and value ambience and a deep sensory and intellectual experience. Finally, individuals with spiritual drivers look for creative stimulation and quiet contemplation; they view museums as an opportunity to escape and recharge their batteries, seeing them as food for the soul. These motivational drivers are hierarchical; social drivers are located at the bottom and spiritual drivers are at the top. In other words, the higher visitors are in the hierarchy, the more fulfilling and rewarding are their visits.

In a more recent research study, Sheng and Chen (2012) explore the components of experience expectations for museum visitors in Taiwan by integrating a content analysis of diaries written by museum visitors into their quantitative research. Their factor analysis identifies five types of experience expectations: (1) easiness and fun, (2) cultural entertainment, (3) personal identification, (4) historical reminiscences and (5) escapism. The authors then compare visitors' museum preferences with their demographic data and find that visitors who enjoy visiting museums usually expect easiness and fun and historical reminiscences. Because of previous impressions or past experiences, individuals with these expectations feel that 
museums can satisfy them. As Weil (2000) suggests, modern museums offer recreation activities, which meet the expectation of easiness and fun. Sheng and Chen (2012) also find that visitor expectation is part of personal context and is influenced by factors such as education and family life cycle. Museum visitors at different stages of their lives have different needs and perceptions.

\section{Methodology}

Results presented in this paper are part of a larger research study that investigated various types of museum visitors and segments. In order to achieve the objectives of the study, face-to-face interviews were conducted with current museum visitors in two main art museums in Genoa, Italy. 400 museum visitors who agreed to participate in the research were interviewed by one of the authors, as well as by a graduate student trained and monitored by that author. Interviews were conducted in a range of places, at various times of day and at different periods (between July and August 2014) so that a representative sample could be obtained. As part of the interviews, participants were asked to define a museum. The survey instrument was designed in English and translated into Italian and French. The back translation method was used to ensure consistency between the original and translated versions of the definitions made by the respondents. Among the 394 usable questionnaires collected, 372 available definitions were analyzed in this study.

The majority of respondents were from Italy (41.9\%), followed by France $(33.2 \%)$ and other European countries (18.5\%). Regarding Italian respondents, only $13.2 \%$ were from Genoa. The major demographic profiles of respondents indicate that museums in Genoa are mostly visited by women (i.e. 229 females and 149 males) and people between 31 and 60 years old (63.2\%), and those of high socio-economic status $(64.7 \%)$. These findings are in line with large scale research findings (EGMUS 2007; HLF 2012). In the last 12 months, the majority of respondents had visited a museum five times or more $(47.2 \%)$, followed by those who had visited a museum three or more times $(31.2 \%)$, once or twice $(17.8 \%)$ and those who had not visited a museum (3.8\%). The most common motivation for visiting museums was to learn (72.3\%), which confirms the findings of Falk and Dierking (1992), Jansen-Verbeke and van Rekom (1996), and McLean (1994). Museums in Genoa also seem to have a substantial amount of repeat visitors, as $44.9 \%$ of the respondents claimed that they would visit the museum again in the next 12 months.

We used a grounded theory approach to explore the dimensions underlying the museum experience of the visitors by referring to their definitions of a museum. Tung and Ritchie (2011) stated that as an inductive, qualitative research method, grounded theory focuses on data depth and quality for the construction of theory through the analysis of data. We conducted our analysis in three stages. First, we reviewed the definitions collected from the respondents and ran a word frequency query to help us find key themes. Second, as repeated themes, ideas, or concepts 
become apparent from these definitions, we tagged them with descriptive codes. For this purpose, we used a qualitative research software named NVivo 11. As a tool to help reduce time spent to classify, sort, and arrange data, NVivo allows researchers to develop dimensions or sub-dimensions at any time during the data analysis and to reduce, alter or enhance them even further when necessary. In the last stage, we reduced the descriptive codes to interpretative themes by checking them against categories used in literature. Although this provided us helpful validation, we remained open to the data in order to allow for theoretical concepts to emerge.

\section{Results}

While defining the museum in mind, respondents used the following words the most:

- "Place" 189 times

- "Culture/cultural" 94 times, "heritage" 12 times

- "History/historical" 78 times, "past" 46 times, "memory" 20 times

- "Present" 13 times, "Future" 10 times, "new" 16 times

- "Art/artist/artistic/artwork" 73 times, "beauty/beautiful" 26 times

- "Learn/learning" 63 times, "knowledge" 26 times, "discover/discovery" 16 times, "see" 16 times, "wonder" 16 times, "education" 4 times, "information" 4 times

- "Interesting" 28 times, "entertaining/entertainment" only 2 times

- "Boring" 4 times, "death", "sad" and similar negative words only three times in total

Accordingly, Fig. 1 illustrates a word-cloud representing respondents' top-of-mind associations of museums. Based on this, we may claim that respondents mostly see museums as a place and associate it with culture, history, art and learning. As most frequently cited verbs include "learn", "wonder" and "see", museums are places to learn, wonder and see, new and different things.

From the definitions of the visitors, seven themes (components) were identified which represent aspects of visitors' experiences in museums. In order of importance in line with frequency counts, they are experiences that provide (1) historical and/ or cultural reminisce and awareness, (2) learning and self-development, (3) exposure to tangible evidences, (4) sensory stimulation, (5) wonder and discovery, (6) entertainment and (7) socializing.

With regard to historical and/or cultural reminisce and awareness, positive feelings and emotions associated with the experiences (such as having good time, amazement, excitement, happiness) were described by the majority of the respondents as a critical component of their museum definitions. After describing museums as places associated with history, culture and art, respondents often provided more details of their museum experiences as in the following: 
Fig. 1 Word-cloud representing respondents' top-of-mind associations of museums derived from their definitions of a museum

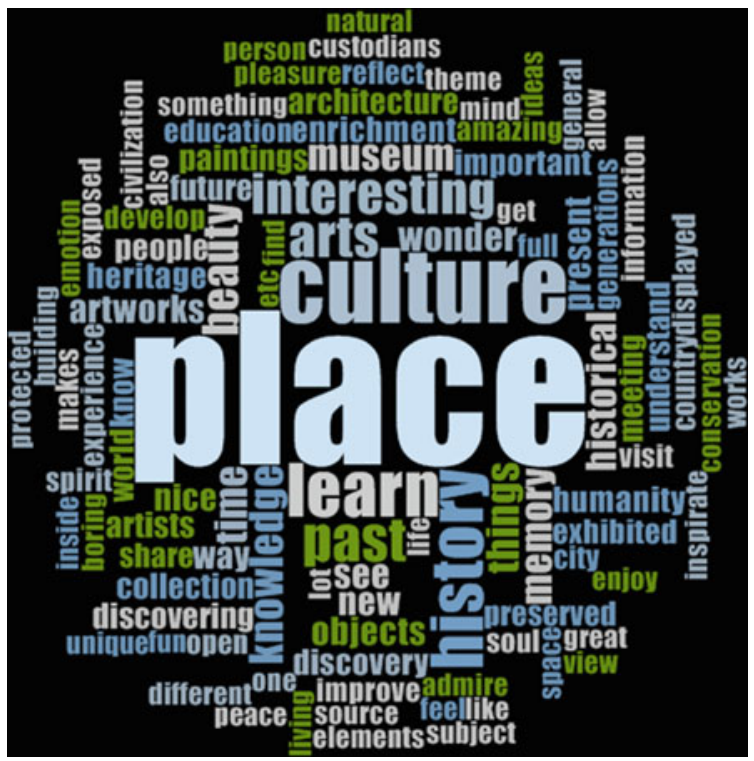

Place to keep, save cultural, national, historical heritage and knowledge, to make this heritage and knowledge known to people and present it in a way that makes people aware about their importance and beauty to ensure that they are kept for future generations" (Female, art historian, Austria).

Place of culture in order to learn and understand our past" (Male, employee, Parma Italy). Place of culture, amazement and heritage conservation (Female, teacher, France).

Places of culture and memory, places that express the history of a country 'Contemplation of beauty'. Educating to appreciate the beauty (Female, teacher, Rome Italy).

Museums are places where history, art, architecture combine to enrich and excite the visitor and you come out happier than you have entered (Male, pharmacist, Turin Italy). A meeting with the history. It is the way the past can speak to the men of present times (Female, teacher, Naples Italy).

Places to learn, admire, that helps us to get in touch with history of humankind and culture (Female, artist, Poland).

Learning and self-development were reflected in definitions emphasizing learning, enrichment and personal growth. Museums are so highly valued and positively regarded because of the educational purposes they are perceived to hold. It involved many references such as learning the history, local culture, way-of-life, and something new. These are explored in the following examples:

A place to learn a bit of art, a bit of history and a place to have good time (Female, entrepreneur, Spain).

A place or resource created to visit that educates and stretches the mind by opening your eyes to the wonder of art/science/man's achievement. (Female, garden designer, UK).

A place to dream, learn, grow up (Female, project manager, France). 
Places to learn, reflect, consider, reconsider and wonder (Male, teacher, UK).

Places to expand your mind and experience (Male, retired university lecturer, UK).

A place where one comes out "smarter" and cultivated than entered (Female, genealogist,

France).

Beautiful! Magnificent! A place where we can learn and develop (Female, nurse, Canada).

While defining museums, many respondents also expressed gratitude that they are able to see and are exposed to valuable and rare objects in museums. Exposure to tangible evidences was reflected in those definitions that suggested some sort of importance given to joy of seeing materials and objects on display.

A place where to learn about the art from the 'original' (Female, teacher, Milan Italy).

Place of exposure of objects that allow enriching the knowledge of persons (Male, merchant, Milan Italy).

Places where things of the memory are displayed to last in time to witness the past to the future (Female, employee, Cremona Italy).

A place where interesting things can be seen (Male, veterinary, Ivrea Italy).

A unique place where you can imagine or see how it was in the past. Where you can be in the same room (atmosphere) (Female, logistics, France).

A place to learn and discover beautiful works on display. A place between virtual, imagination and reality (objects exposed) (Female, public officer, France).

Museums are teaching you about the past in a visual way. If you don't like to read books or receive a lot of information at once, the museum is an ideal way of getting an idea of how life was before (Female, teacher, Genoa Italy).

Sensory stimulation was reflected in definitions emphasizing various positive sensory and spiritual feelings and emotions that respondents experience in museums. Amazement, excitement, and reflection were among those feelings and emotions described by the majority of the respondents.

A place to get inspired, surprised, enriched (Female, company director, The Netherlands). A place where I learn and I am amazed. It reminds me of the Bible, mythology, history in general (Female, student, France).

Wealth of the soul (Female, sculptor, Florence Italy).

Memory and youth, not only a historical site but soul, inspiration and civilization (Male, lawyer, France).

Places that inspire you (Male, farmer, Belgium).

Place of interest and culture where you can spend your time in peace and harmony with the art that surrounds you (Female, employee, Florence Italy).

A place to exercise the spirit (Male, employee, Milan Italy).

Wonder and discovery were reflected in definitions specifically addressing descriptions of wonder and discovery encountered during museum visits. In these definitions, respondents mostly emphasize that they enjoy learning or seeing new things. The following definitions include descriptions of such experiences:

A world of wonder (Female, civil servant, UK).

A place of cultural discovery (Male, consultant, France).

Place of culture, wealth, discovery and rediscovery of values. The place where the greatest feelings are expressed (Female, teacher, Rome Italy).

Place where you can discover the culture of the country you visit and the objects of the past centuries for the pleasure of learning and observing (Female, surgical assistant, France). 
Relation between culture, pleasure, and cultural discovery (Male, lawyer, France).

The place where I discover something new (Male, merchant, Japan).

Museums mean for me a very nice way of learning new things, of seeing new things and of discovering things about our past (Male, student, Romania).

Although entertainment was not reflected often in definitions made by the respondents, there are still some examples for those fun and entertaining experiences in museums.

Places to learn. Places to see exhibitions from other countries and cultures. Places which keep the treasure of your own country. Great entertainment on a rainy day! (Female, retired, UK).

Place where you can learn a lot, playful, attractive (Female, unemployed, France).

Place of interest, sharing and fun (Female, teacher, La Spezia Italy).

Fun places (Female, retired, Finale Italy).

Conservation, animation, exhibition, meditation (Female, designer, France).

Amazing, fun, joyful (Female, student, France).

Socializing is another element not often reflected in the definitions. In these available definitions, respondents mostly mention museums as meeting places to share with others.

Museums should also be meeting places for sharing ideas as in London (Female, housewife, Varese Italy).

Places of culture, emotions, aesthetic enjoyment, meeting (Male, employee, Genoa Italy).

A friendly space, culture and sharing (Male, school director, France).

Places of knowledge and meeting (Male, student, Genoa Italy).

Place to share extraordinary artworks (Female, psychologist, France).

Finally, in addition to these themes explored above, a number of respondents defined museums as places for protection and preservation. When defining museums, it was clear that respondents emphasized the purpose of museums in safeguarding historical objects and cultural heritage and preventing them from being lost. Care and preservation of heritage is viewed as being an important function of museums. Accordingly, in the following definitions, respondents emphasized preservation to ensure the past is kept safe and learnt from.

Place where cultural heritage is preserved and exhibited (Female, professor, France).

Museums are an open box of beauty, past and future (Female, advisor, UK).

A place where historic collections are preserved and shared with the public (Male, IT manager, The Netherlands).

Protected reserve of the traces left by humanity through ages (Male, designer, France).

A place where the past is protected (Female, professor, France).

Places of cultural interest where objects and theme stories are preserved for us and our future generations (Female, curator, The Netherlands).

Special place to get to know and preserve the cultural and artistic heritage (Male, doctor, Switzerland).

From the definitions made by the participants, it is evident that a museum visitor can experience various influences of different elements in a museum. Museum visitors in general seem to be capable of having a number of different kinds of 
visitor experiences. Nevertheless, regarding the discussions concerning the content of experience, scholars agree on the fact that "experience usually includes various elements, and it provides an emotionally, physically, intellectually and spiritually mixed feeling" (Sheng and Chen 2012: 53).

\section{Conclusion}

As important cultural organizations in the service of society, museums have been going through a change from being predominantly custodial institutions to becoming increasingly focused on audience attraction (Gilmore and Rentschler 2002). In order to increase visitation and survive in the long run, today's museums need to understand their visiting publics involving cultural tourists.

As pointed out by Brida et al. (2013), for a long time, visitors of cultural attractions were assumed homogeneous. However, recent literature suggests that visitors of cultural attractions are made up of a heterogeneous market with different characteristics, perceptions and needs. Thus, this research aimed to understand various publics, their perceptions and experiences in museums. The findings of this research confirm that as the most popular cultural attractions usually followed by art galleries and monuments, museums offer visitors different kinds of experiences. As Falk (1998) stated, museum-going is a complex subject and the measurement of demographic categories alone cannot offer much insight into understanding visitors. Therefore, in order to offer exhibitions and services that visitors look for, an attempt have been made in this research to understand why people visit museums, how they feel there and what meaning they take from the experience by conducting a qualitative research.

The analysis of the museum definitions of the respondents in this study revealed seven core factors of museum visitor experience. These museum experiences provide visitors historical and/or cultural reminisce and awareness, learning and self-development, exposure to tangible evidences, sensory stimulation, wonder and discovery and to a lesser level entertainment and socializing. However, the findings of this research confirm Falk (2009) that museum visitor experience is a series of nested and seemingly interrelated experiences as most of the definitions of the respondents included various elements (themes). In addition, every visitor is a unique individual capable of having a wide range of different kinds of visitor experiences but most of them seem to select from a limited palette of possible experiences.

These results provide important implications. In this research, an attempt has been made to explore common experience characteristics in multiple visitor experiences. As pointed out by Sheng and Chen (2012), this subject is rarely studied and investigated in studies on museum visitors. However, without distinguishing the common characteristics of experience, it is difficult to measure and understand visitor experiences. Hence, the findings of this research can help managers develop and design measurement tools to understand visitor satisfaction in their museum. The findings can also help managers segment the visitors based on 
their experience expectations to develop the right marketing strategies. In this regard, future research can investigate the possible significant differences of experience expectations of museum visitors with different characteristics. Based on these experience expectations, museum visitors' selection can also be investigated. However, further research might well suggest that within the general museum visitor experiences revealed by this research, there is likely to be much greater complexity when looking at individual experiences and their needs.

This study only focused on visitors of two museums in Genoa Italy, therefore the application scope of the findings is limited. The analysis is also based on a non-random sampling technique. Thus, in order to verify whether the results are valid for other museums, a future study may be conducted in other museums and places.

Acknowledgements The authors wish to acknowledge the valuable help in data collection and support for this research provided by Dr. Piero Boccardo, Dr. Adelmo Taddei, Dr. Elizabetta Papone, Ms. Tina Russo, Ms. Paola Barbara Villa and the museum community of Genoa, Italy.

\section{References}

ACE Arts Council of England. (2013). Public perceptions of - and attitudes to - the purposes of museums in society. Retrieved January 20, 2016 from https://www.google.com.tr/\#q=arts +council+of+england+public+perceptions+march+2013.

Brida, J. G., Disegna, M., \& Scuderi, R. (2013). Visitors of two types of museums: A segmentation study. Expert Systems with Applications, 40, 2224-2232.

Caru, A., \& Cova, B. (2006). How to facilitate immersion in a consumption experience: Appropriation operations and service elements. Journal of Consumer Behaviour, 5, 4-14.

Caru, A., \& Cova, B. (2008). Small versus big stories in framing consumption experiences. Qualitative Market Research: An International Journal, 11(2), 166-176.

DCMS Department for Culture, Media and Sport. (2010). Understanding the drivers, impact and value of engagement in culture and sport-An over-arching summary of the research July 2010. Retrieved August 12, 2014 from https://www.gov.uk/government/uploads/system/ uploads/attachment_data/file/71231/CASE-supersummaryFINAL-19-July2010.pdf.

Dirsehan, T., \& Çelik, M. (2011). Profiling online consumers according to their experiences with a special focus on social media. Procedia-Social and Behavioral Sciences, 24, 401-412.

EGMUS European Group on Museum Statistics. (2004). A guide to European museum statistics. Retrieved June 27, 2010 from http://culturaincifre.istat.it/sito/musei/Guide_to_European_ Museum.pdf.

EGMUS European Group on Museum Statistics. (2007). European cultural values. Retrieved August 12, 2014 from http://www.egmus.eu/fileadmin/statistics/themes/Management/994_ Special_Eurobarometer_278.pdf.

Falk, J. H. (1998). Visitors: who does, who doesn't and why. Museum News, March/April, 38-43.

Falk, J. H. (2009). Identity and the museum visitor experience. Walnut Creek: Left Coast Press Inc.

Falk, J. H., \& Dierking, L. D. (1992). The museum experience. Washington, DC: Whalesback Books.

Falk, J. H., \& Dierking, L. D. (2000). Learning from museums: visitors experiences and the making of meaning. Walnut Creek: AltaMira Press.

Firat, A. F., Dholakia, N., \& Venkatesh, A. (1995). Marketing in a postmodern world. European Journal of Marketing, 29(1), 40-56. 
Fitchett, J. (1997). Consumption and cultural commodification: The case of the museum as Commodity (Unpublished doctoral dissertation). University of Stirling, Scotland.

Gilmore, A., \& Rentschler, R. (2002). Changes in museum management-A custodial or marketing emphasis? Journal of Management Development, 21(10), 745-760.

Günlü, E., Yağcı, K., \& Pırnar, İ. (2009). Preserving cultural heritage and possible impacts on regional development: Case of İzmir. International Journal of Emerging and Transition Economics, 9, 213-229.

Harrison, P., \& Shaw, R. (2004). Consumer satisfaction and post-purchase intentions: An exploratory study of museum visitors. International Journal of Arts Management, 6(2), 23-32.

HLF Heritage Lottery Fund. (2012). Values and benefits of heritage - A research review. London: Heritage Lottery Fund Strategy and Business Development Department. Retrieved August 25, 2015 from http://www.hlf.org.uk/values-and-benefits-heritage.

Hooper-Greenhill, E. (1994). Museums and their visitors. New York: Routledge.

Hosany, S., \& Witham, M. (2009). Dimensions of cruisers' experiences, satisfaction and intention to recommend. Working Paper Series: School of Management, Royal Holloway University of London. Retrieved August 15, 2016 from http://poseidon01.ssrn.com/delivery.php?ID= 112001112005007070029127007125018071053009053038065056030072021066020092100 004095094098007039126015013042087121029027078112119027039038017006094066004 067010123005093039032030000082107119027005105026024112005126105065069104115 089064071030008123099125071\&EXT=pdf.

Hughes, H. (1996). Redefining cultural tourism. Annals of Tourism Research, 23, 707-709.

ICCROM International Center for the Study of the Preservation and the Restoration of Cultural Property. (2005). Definition of cultural heritage-References to documents in history. Retrieved August 9, 2014 from http://cif.icomos.org/pdf_docs/Documents\%20on\%20line/ Heritage\%20definitions.pdf.

ICOM International Council of Museums (2014). Development of the museum definition according to ICOM Statutes 2007-1946. Retrieved May 31, 2014 from http://archives.icom. museum/hist_def_eng.html.

Jansen-Verbeke, M., \& van Rekom, J. (1996). Scanning museum visitors - Urban tourism marketing. Annals of Tourism Research, 23(2), 364-375.

Kotler, N., \& Kotler, P. (2000). Can museums be all things to all people? Missions, goals and marketing's role. Museum Management and Curatorship, 18(3), 271-287.

Kotler, N., \& Kotler, P. (1998). Museum marketing \& strategy-Designing missions, building audiences, generating revenue \& resources. San Fransisco: Jossey-Bass.

Kotler, N., Kotler, P., \& Kotler, W. (2008). Museum marketing and strategy (2nd ed.)—Designing missions, building audiences, generating revenue and resources. San Francisco: Jossey-Bass.

Lin, Y. (2006). Leisure-A function of museums? The Taiwan perspective. Museum Management and Curatorship, 21, 302-316.

Malde, S. (2013, April 2). Museums connecting cultural tourists: more substance over style, please. The Guardian. Retrieved January 31, 2016 from http://www.theguardian.com/cultureprofessionals-network/culture-professionals-blog/2013/apr/02/museums-cultural-touristsdigital-content.

McLean, F. (1994). Services marketing: The case of museums. The Service Industries Journal, 14 (2), 190-203.

McLean, F. (1995). A marketing revolution in museums? Journal of Marketing Management, 11, 601-616.

MLA Museums, Libraries and Archives Council. (2005). Digest of statistics for museums, libraries and archives. London: MLA.

MORI Market Opinion and Research International. (2004) Visitors to museums and galleries 2004 -Research study conducted for the museums, libraries and archives council March 2004 (revised November 2004). London: MORI.

MORI Market Opinion and Research International. (2005). Renaissance in the regions — Final national report 2004 (Unpublished). 
Morris Hargreaves McIntyre (2007). Audience knowledge digest: Why people visit museums and galleries, and what can be done to attract them March 2007. Manchester: Morris Hargreaves McIntyre. Retrieved August 13, 2014 from http://webarchive.nationalarchives.gov.uk/ 20120215211132/research.mla.gov.uk/evidence/documents/audience\%20knowledge\% 20digest.pdf.

Newsweek. (2004, 9 August). The museum wars-Europe's great art institutions are racing to transform themselves into modern centers of entertainment. Retrieved May 29, 2011 from http://www.newsweek.com/museum-wars-126333.

Oh, H., Fiore, A. M., \& Jeoung, M. (2007). Measuring experience economy concepts: Tourism applications. Journal of Travel Research, 46(November), 119-132.

Pine, B. J., \& Gilmore, J. (1999). The experience economy: Work is theatre and every business a stage. Boston: Harvard Business School Press.

Prentice, R., Davis, A., \& Beeho, A. (1997). Seeking generic motivations for visiting and not visiting museums and like cultural attractions. Museum Management and Curatorship, 1, 4570.

Pulido-Fernandez, J., \& Sanchez-Rivero, M. (2010). Attitudes of the cultural tourist: A latent segmentation approach. Journal of Cultural Economics, 34, 111-129.

Rentschler, R. (2007). Museum marketing: No longer a dirty word. In R. Rentschler \& A. Hede (Eds.), Museum marketing-competing in the global marketplace (pp. 12-20). Oxford: Elsevier.

Richards, G. (1994). Developments in European cultural tourism. In V. Seaton (Ed.), Tourism: The state of the art. London: Wiley.

Roberson, D. N. (2011). Free time in an art museum: Pausing, gazing and interacting. Leisure Sciences, 33, 70-80.

Schmitt, B. H. (1999). Experiential marketing. Journal of Marketing, 15(1), 53-67.

Sheng, C., \& Chen, M. (2012). A study of experience of museum visitors. Tourism Management, 3, 53-60.

Thyne, M. (2001). The importance of values research for nonprofit organisations: The motivation-based values of museum visitors. International Journal of Nonprofit and Voluntary Sector Marketing, 6(2), 116-130.

Tung, V. W. S., \& Ritchie, J. R. B. (2011). Exploring the essence of memorable tourism experiences. Annals of Tourism Research, 38(4), 1367-1386.

Weil, W. E. (2000). Transformed from a cemetery of bric-a-brac. In B. Shepperd (Ed.), Perspectives on outcome based evaluation for libraries and museums (pp. 4-12). Washington DC: Institute of Museum and Library Services.

Yau, R. (2001). Museums are for people. Hong Kong: Leisure and Cultural Services Department. Retrieved May 29, 2011 from http://www.lcsd.gov.hk/ce/Museum/History/en_US/web/mh/ publications/spa_pspecial_04_0.html.

Yen, J., \& Lin, C. (2005). Museum marketing and strategy: Directors' perception and belief. Journal of the American Academy of Business, 6, 279-284. 